\title{
Decision to forgive scale and emotional forgiveness scale in a polish sample
}

\author{
Justyna Mróz ${ }^{1}$ (D) $\cdot$ Kinga Kaleta $^{1} \cdot$ Ewa Sołtys $^{2}$ \\ Published online: 16 June 2020 \\ (C) The Author(s) 2020
}

\begin{abstract}
The paper presents the concept of emotional and decisional forgiveness proposed by Worthington et al. (Journal of Behavioral Medicine, 30, 291-302, 2007) and employing the Polish versions of the Decision to Forgive Scale and Emotional Forgiveness Scale developed in line with this theory. Both scales are tools measuring episodic forgiveness is forgiveness for a specific transgression that is made once. Decisional forgiveness is a declaration to forgive, whereas emotional forgiveness is a "change of heart". The results of exploratory factor analysis and confirmatory factor analysis showed that the structure of the Polish scales is exactly the same as of the original tools, i.e., in case of the DTFS, a one-factor solution (CFI $=.998$, GFI $=.990$, RMSEA $=.042)$, and in case of the EFS, a two-factor solution $(\mathrm{CFI}=.987$; GFI $=.984$; RMSEA $=.051)$. The Polish versions of the DTFS and EFS were significantly correlated with other tools of forgiveness (TRIM-18 - episodic forgiveness and HFSdispositional forgiveness).
\end{abstract}

Keywords Emotional forgiveness $\cdot$ Decisional forgiveness $\cdot$ Adaptation

\section{Introduction}

Although psychologists have continued to discuss the fundamental dimensions of forgiveness, they all agree that forgiveness engages a positive psychological change toward the offender (McCullough et al. 2006). The shift takes place in cognition (Thompson et al. 2005), emotions (Malcolm and Greenberg 2000), motivations (McCullough et al. 1997), or behaviors (Dorn et al. 2014). Researchers have emphasized the role of specific aspects of forgiveness, or defined it as a complex construct (e.g. Enright 1996). Worthington described two kind of forgiveness: decisional - a decision to control person's behaviors toward the transgressor, and multifaceted emotional - involving modified emotions, and consequently cognition and motivations (see Exline et al. 2003; Worthington et al. 2007). Though related, decisional and emotional forgiveness constitute various processes resulting in various outcomes (Hook et al. 2009). Emotional forgiveness

Justyna Mróz

jmroz@ujk.edu.pl

1 Department Psychology, Jan Kochanowski University in Kielce, Krakowska 11, 25-029 Kielce, Poland

2 Department Psychology, University of Wroclaw, Wroclaw, Poland is strongly associated with overcoming negative stress reactions by replacing emotions, which are negative, as vengefulness, anger with positive emotions, as benevolence and charity (Berry et al. 2005). In turn, decisional forgiveness, although it might reduce hostility and lead to reconciliation, does not necessarily reduce stress responses (Worthington et al. 2007). Having different sequelae and, probably, antecedents, these two distinct types of forgiveness should be measured separately and directly.

Worthington and colleagues (Watkins et al. 2011; Hook et al. 2012; Scherer et al. 2012; Davis et al. 2015) developed and used two separate scales measuring decisional and emotional forgiveness. The aim of this study is to present the process of adaptation of the Decision to Forgive Scale (DTFS; Davis et al. 2015) and the Emotional Forgiveness Scale (EFS; Hook et al. 2012) to be able to use it in a Polish sample.

\section{Decisional Forgiveness}

Decisional forgiveness is viewed as "the cognitive letting go of resentment and bitterness and need for vengeance" (DiBlasio 1998, p. 78). Decisional forgiveness incorporates an intellectual dimension (Fitzgibbons 1986) and modifies one's intentions as to one's behavior toward an transgressor, in particular motivation for revenge and avoidance (Exline 
et al. 2003). Worthington (2005), just like Fitzgibbons (1986), indicated that a decision to control one's behaviors is one of the two types of forgiveness, along with emotional forgiveness. The reduction of negative thoughts may or may not involve decrease in negative emotions toward the wrongdoer. This provides grounds for the separation of the cognitive and emotional processes.

The victim's conscious commitment is particularly important; the decision to forgive is an act of will, and a deliberate choice. Some researchers (f.e., Davis et al. 2015) draw attention to the victim's declaration to forgive their offender. People can declare to forgive under different circumstances, such as pressure of the family, community, or religion, or ultimately as a result of psychotherapy (e.g. Fitzgibbons 1986). It is pivotal moment in the process of forgiving. Individuals making the involvement to forgive, evaluate how much energy, effort and time they need to do it. However, sometimes this isn't possible, as the wrongdoing is too recent or it continues. Additionally, it must be stressed that the decision to forgive is not tantamount to the process of forgiving (Davis et al. 2015).

Moreover, the process of forgiveness begins after the therapist, together with a patient, have analyzed the patient's harm, and this may lead to making the decision to forgive (Fitzgibbons 1986). Additionally, decisional forgiveness is the first step to complete forgiveness.

\section{Emotional Forgiveness}

Although decisional forgiveness is crucial to achieving forgiveness, Worthington (2009, p. 41) referred to emotional forgiveness as the type of forgiveness "that changes the heart". He (Worthington and Scherer 2004) and other emotionally oriented researchers (Fitzgibbons 1986; DiBlasio 1998) have argued that forgiveness is essentially the process of emotion regulation, decreasing negative feelings such as anger, anxiety, hatred, and evoking positive feelings like sympathy, pity, love (Worthington and Scherer 2004). They emphasize that there is more to forgiveness than just reducing unforgiveness, involving delayed negative emotions along with rumination and motivated avoidance or revenge against an offender, because this might be done in several ways without forgiveness to occur (Worthington 2009). Forgiveness is an inner choice not only to give up estrangement or vengeance but also to seek conciliation or reconciliation, provided this is safe and possible. However, this choice is facilitated by emotional states which are incongruent with unforgiveness. The authors (Worthington and Wade 1999) described the entire process of this emotionally conceptualized tendency to forgive in the context of ongoing connection which in fact demand a lot of forgiveness.

Usually after having been hurt, offended or unjustly treated, a person reacts emotionally with anger, hostility, anxiety or fear (Worthington and Wade 1999). These emotions and their consequences stimulate a person to relieve distress. There are many common strategies, including retaliation or avoiding the offender (McCullough et al. 1997), seeking justice, denying or minimizing the harm, accepting the transgression, projecting, self-blaming, etc. (Worthington and Wade 1999; Worthington 2009). Some of them help reduce unforgiveness, whereas other promote resentment. Among several possible methods to deal with a hurt, forgiveness is the only one that helps deal directly with the transgression and regain a positively valenced relationship.

Emotionally oriented scholars have indicated that forgiveness is "facilitated by events that produce an emotional state, such as empathy, humor, or love, that competes with the cold emotion of unforgiveness" (Worthington and Wade 1999, p. 386). Such events include receiving reasonable explanation, apology, perpetrator's attempts to compensate for a wrong, recalling good memories about the relationship, or sharing affection. They create emotional dissonance with the victim's negative feelings and push the person to seek resolution. Emotional dissonance can be favorably resolved through somatic, cognitive, or environmental predominance of positive affect, e.g. by willful concentrating on positive emotions and changes in the perception of the wrongdoing (Worthington and Wade 1999). At first, positive emotions neutralize malevolent feelings, entailment of a diminishment in negative affect. Next, when the negative feelings are prominently eliminated, positive emotions can be emerged (DiBlasio 1998; Exline et al. 2003). This transformation of feelings and thoughts entails motivation to have a good relationship with an undeserving perpetrator. All these psychological changes move a person not only toward forgiveness and to reconciliation, but they also result in improvement of one's overall health and wellbeing (Worthington et al. 2007; Witvliet et al. 2011).

Both the therapeutic process and research on forgiveness require precise measurement of decisional and emotional forgiveness. This might be done using the Decision to Forgive Scale and the Emotional Forgiveness Scale.

\section{Original Tools}

The scales measuring decisional and emotional forgiveness were developed by Worthington and colleagues. The Decision to Forgive Scale (DTFS; Davis et al. 2015) is the second version of the scale measuring a person's level of decisional forgiveness in one specific situation. The first version of the scale had eight items and two subscales, the Prosocial Intentions Subscale and Harmful Intentions Subscale. However studies, although few, indicated that this scale had poor evidence for divergent validity with another scale measuring episodic forgiveness i.e. TRIM, which is a substantial limitation. Davis et al. (2015) developed a new 
measure of making a decision to forgive and distinguished it conceptually and empirically from the TRIM. New version of the scale has five items rated on a 5-point scale ranging from 1 (strongly disagree) to 5 (strongly agree). The confirmatory factor analysis indicated that the one-factor model showed an adequate fit (CFI). The test-retest correlation for the DTFS was .68 $(p<.001)$. Internal consistencies was .91 (Davis et al. 2015). The DTFS was correlated with TRIM, positively with benevolence, and negatively with revenge and avoidance (Recoder et al. 2019; Bartholomaeus and Strelan 2016).

Studies on decisional forgiveness have used two measures: the previous DFS (Decisional Forgiveness Scale) and the current DTFS (Decision To Forgive Scale). Using DFS, Kurniati with colleagues (Kurniati et al. 2017) found link between the decision to forgive and rumination (negative), and between the decision to forgive and harmonious values (positive). There are a few studies employing DTFS. For example, Bartholomaeus and Strelan (2016) who explored the justworld beliefs, implicit theories of relationships and forgiveness, revealed that the belief in a just world for oneself and growth beliefs were positively correlated with decisional forgiveness, however the belief in a just world for others and destiny beliefs were insignificantly correlated with decisional forgiveness. On the other hand, Recoder with colleagues (Recoder et al. 2019) found relationship between decisional forgiveness and state anger (negative), empathy and life satisfaction (positive).

The Emotional Forgiveness Scale (EFS) measures emotional forgiveness and peace for a particular offence. The scale was used and described in several studies (Watkins et al. 2011; Hook et al. 2012; Scherer et al. 2012; Duggi and Kamble 2014; Bartholomaeus and Strelan 2016). The EFS consists of eight items rated on a 5-point scale ranging from 1 (strongly disagree) to 5 (strongly agree) and divided into two 4-item subscales. The first subscale measures presence of positive and prosocial feelings toward the transgressor. The second subscale measures reduction of negative feelings toward the wrongdoer. The higher the score in each subscale, the more forgiveness toward a transgressor a person displays. As reported by Watkins et al. (2011), the EFS was associated with other measures of episodic forgiveness, tendency to forgive, forgiveness-related constructs showing evidence of construct validity.

In a Nepalese sample, emotional forgiveness predicted conciliatory behaviors (positively) as well as avoidance and revenge motivations (negatively), and showed no relationship with individualism or collectivism (Watkins et al. 2011). Hook et al. (2012) who examined the collectivist worldview revealed that it is negatively related to emotional forgiveness in its negative subscale - if a person's self-construal was more collectivist, he or she reported more negative feelings toward the transgressor (e.g., more animosity, grudge).
Thus, DTFS and EFS were used in samples coming from different cultures and they revealed interesting findings. Polish version of the two measures might be useful in research on forgiveness experienced by people in that area. For this reason, we have made efforts to adapt the scales.

\section{Methods}

\section{Participants}

Data collected from 650 adults (149 males and 495 females, 6 failed to indicate their gender) representing central, northern, and western regions of Poland. Their age ranged from 18 to 79 years, $(M=27.86 ; S D=11.05)$. The majority of respondents lived in cities (49.8\%), 33.02\% in the country, $17.13 \%$ in towns. Their education levels ranged from vocational education $(3.51 \%)$, through secondary $(53.24 \%)$, and college $(6.79 \%)$ to higher education (35.88\%). Finally, $69.77 \%$ of the respondents were never married, $25.5 \%$ were married, $3.21 \%$ divorced, and $0.46 \%$ widowed. For further calculations, we qualified 639 questionnaires with complete information. The participants volunteered (without any financial reward) to take part in the study. They were recruited by university students. They answered all the questions in private, and returned the completed the set of tools.

\section{Measures}

We used the following measures in the study.

Episodic Forgiveness Transgression-Related Interpersonal Motivations Inventory (TRIM-18; McCullough et al. 2006; Polish adaptation Kossakowska and Kwiatek 2017). TRIM18 is an 18-item self-report inventory measuring motivations toward a specific offender, and includes three scales: Revenge (5 items), Avoidance ( 7 items), and Benevolence (6 items). The TRIM has a 5-point response scale. The Cronbach's alpha were found from .86 to .94 (McCullough et al. 2006).

Dispositional Forgiveness The Polish version of Heartland Forgiveness Scale (Thompson et al. 2005; Polish adaptation, Kaleta et al. 2016). HFS is a multidimensional questionnaire measuring disposition to forgive of self, others, and situations beyond anyone's control. Respondents rate their answers to 18 items, using a scale from 1 (absolutely false) to 7 (absolutely true). The Polish version consists of two scales that allow to measure the tendency to forgive - positive (P scale) and negative ( $\mathrm{N}$ scale). In this study we used only three indices: total forgiveness, $\mathrm{P}$ scale and $\mathrm{N}$ scale. Internal consistencies ranged from .70 to .81 (Kaleta et al. 2016). 
Rumination and Reflection The Polish abridged version of The Rumination-Reflection Questionnaire (RRQ; Trapnell and Campbell 1999; Radon 2014). This scale measures the tendency to engage in ruminative and reflective thinking. Ruminative thinking is defined as neurotic, motivated by perceived threats or potential losses. On the other hand, reflective thinking is found as more intellectual, involving curiosity or searching for understanding of things that happen. There are 13 items; 6 are used to assess the ruminative style (from 6 to 30 points) and 7 to rate the reflective style (from 7 to 35 points). The participants indicate their response on a 5-point scale (1-strongly disagree to 5-strongly agree).

To measure the level of positive and negative affect we used the Positive and Negative Affect Schedule (PANAS; Watson et al. 1988; Polish version of the scale: SUPIN C30; Brzozowski 2010). The scale consists of 30 items (15 items positive affectivity; 15 items - negative affectivity). Using a 5point scale, the respondents were asked to rate the extent to which they usually experience each of the emotions. Internal consistencies from .73 to .95 (Brzozowski 2010).

Mental Health General Health Questionnaires (GHQ-28; Goldberg 1978; Polish version Makowska and Merecz 2001) consisting of four 7-item scales: somatic symptoms, anxiety and insomnia, social dysfunction and severe depression. It allows to assess one's mental health according to four dimensions corresponding to these scales. The subjects indicate their response on a 4-point scale (f.e. from not at all to much more than usual). Cronbach's alpha for the GHQ-28 ranged from .79 to .88 .

\section{Data Analysis}

Firstly, the factor structure of DTFS and EFS was examined using the EFA and CFA. Secondly, the reliability of the DTFS and EFS was analyzed. Thirdly, we analyzed the criterion validity for DTFS and EFS. The relationships between decisional and emotional forgiveness, and the disposition to forgive, episodic forgiveness (motivation for revenge, avoidance and benevolence), positive-negative affect, rumination, reflection, and mental health were studied using Pearson's correlations. Data were analyzed using STATISTICA 13.1.

\section{Results of the Psychometric Analyses}

\section{Factor Structure}

We evaluated the factor structure of both scales. We randomly split the participants into two groups. In the first step, we conducted an exploratory factor analysis (EFA) of the former group. Both DTFS and EFS showed an exactly the same structure as in the original tools, i.e. DTFS a one-factor, and
EFA a two-factor model (Tables 1 and 2). In the second step, CFA was conducted of the latter group.

Decision to Forgive Scale The exploratory factor analysis found a one-factor model corresponding to the structure proposed by authors of the original instruments (Table 1). Similarly, the confirmatory factor analysis also indicated one factor. The obtained Chi square $(\mathrm{X} 2=7.84 ; \mathrm{df}=5 ; p=.16)$ and goodness of fit results $(\mathrm{CFI}=.998, \mathrm{GFI}=.990$, RMSEA $=.042$ ) suggest data consistency model.

Emotional Forgiveness Scale In the exploratory factor analysis, the EFA showed a two-factor model; only item 4 produced a lower factor 1 loading (see Table 2). In addition, CFA exhibited a good fit with the structure of the second scale. We examined three models. First, the one-factor model with the total score only: $\mathrm{X} 2=311.09, \mathrm{df}=20, p<.001$ (CFI $=.632$, $\mathrm{GFI}=.770, \mathrm{RMSEA}=.238)$. Second, the two-factor model: $\mathrm{X} 2=58.018, \mathrm{df}=20, p<.001(\mathrm{CFI}=.952, \mathrm{GFI}=.958$, RMSEA =.074). Third, the two-factor model with the overriding general score: $\mathrm{X} 2=22,317, \mathrm{df}=12, p<.001$ $(\mathrm{CFI}=.987$; GFI = .984; RMSEA $=.051)$.

Reliability of the Polish Versions of DTFS and EFS The reliability of the DTFS and EFS subscales were tested by calculating their internal consistencies. Cronbach's alpha values were obtained for the total DTFS and EFS with the subscales. As can be seen in Table 3, alpha values for DTFS and EFS subscales and for the scale as a whole, demonstrated good internal reliability, with alpha levels comparable to those obtained in the original versions of these scales (Davis et al. 2015; Hook et al. 2012; Scherer et al. 2012; Watkins et al. 2011).

\section{Internal Consistencies}

Descriptive Statistics Mean scores and standard deviations for decisional and emotional forgiveness, as well as their mutual relationships were presented in Table 3. Decision to forgive correlated positively with positive emotional forgiveness, and negatively with negative emotional forgiveness. Positive emotional forgiveness demonstrated an inverse correlation with negative emotional forgiveness.

Table 1 Exploratory factor analysis for DTFS

\begin{tabular}{ll}
\hline DTFS & Factor 1 \\
\hline Item 1 & -.91 \\
Item 2 & -.82 \\
Item 3 & -.94 \\
Item 4 & -.94 \\
Item 5 & -.61 \\
\hline
\end{tabular}


Table 2 Exploratory factor analysis for EFS with two factors: positive emotional forgiveness and reduction of negative emotional forgiveness

\begin{tabular}{lll}
\hline EFS & Factor 1 & Factor 2 \\
& $\begin{array}{l}\text { Positive emotional } \\
\text { forgiveness }\end{array}$ & Reduction of negative \\
& emotional forgiveness
\end{tabular}

\begin{tabular}{lcc}
\hline Item 1 & .92 & \\
Item 2 & & -.55 \\
Item $3^{*}$ & & -.80 \\
Item 4 & .32 & \\
Item 5* & & -.81 \\
Item 6 & .90 & \\
Item 7* & & -.80
\end{tabular}

Item 8

*recoded

Internal Validity We verified the correlation between DTFS and EFS subscales and other measures: TRIM-18 (episodic forgiveness) and Heartland Forgiveness Scale (dispositional forgiveness) (Table 4) for to assess the internal validity of DTFS and EFS

We expected to find significant correlations between DTFS, EFS and TRIM-18, which has been confirmed in the results. Both DTFS and Positive EFS were inversely correlated with the avoidance and revenge, and positively correlated with benevolence motivation. On the other hand, Negative EFS was positively correlated with the motivation to avoid and motivation to seek revenge, and negatively correlated with benevolence motivation. Though the relationships between DTFS and EFS and the tendency to forgive (HFS) were in most cases statistically significant, they were negligible. However, these relationships were weaker than between DTFS, EFS and TRIM-18. Apart from reduced forgiveness of self, the decision to forgive was positively association with the forgiveness. Negative EFS was inversely correlated with all HFS subscales. Positive ETS was significantly correlated only with positive forgiveness, positive forgiveness of others and reduction unforgiveness of others.

External Validity We examined the correlation between the DTFS and EFS subscales and other variables, such as positive and negative affect, psychological well-being, ruminative and reflective thinking (see Table 5) for to assess the external validity of DTFS and EFS.

DTFS was positively correlated with the scores for positive affect and reflective thinking, and negatively with depressive symptoms (GHQ). In turn, EFS, in the reduction of negative emotions dimension, was positively correlated with positive affect whereas inversely with negative affect, GHQ-28 scales with all subscales, and rumination.

\section{Discussion}

The current study explored the psychometric properties of the Polish versions of the Decision to Forgive Scale (Davis et al. 2015) and Emotional Forgiveness Scale (Hook et al. 2012). The scales measure two types of episodic forgiveness.

The assess the construct validity of both scales were realized by exploratory and confirmatory factor analyses. The one-factor model of DTFS and the two-factor model of the EFS recommended by Worthington et al. (2007) were tested and the outcomes pointed that the models met the goodness of fit criteria. Similarly, the reliability analysis indicated favorable results.

As expected, the relationships between DTFS, EFS (positive and reduction of negative feelings) and other scales measuring episodic forgiveness (TRIM-18) were found significant and relatively strongly correlated: positively with benevolence, and negatively with revenge and avoidance. As regards the association with dispositional forgiveness (measured with HFS), correlation coefficients were weaker, and in some dimensions (such as positive EFS and total HFS) non-significant. The outcomes confirmed that both DTFS and EFS measure episodic forgiveness. These results, supported by previous studies, point to disparities between dispositional and

Table 3 Mean scores, standard deviations and correlations between decisional and emotional forgiveness and reliability of the DTFS and EFS Cronbach's $\alpha(N=639) * p<.05$

\begin{tabular}{|c|c|c|c|c|c|c|c|}
\hline & $M$ & $\min -\max$ & $S D$ & DTFS & EFS_total & EFS_pos & $\alpha$ \\
\hline $\begin{array}{c}\text { DTFS } \\
.91\end{array}$ & 16.93 & $5-25$ & 5.14 & - & & & \\
\hline $\begin{array}{l}\text { EFS_total } \\
.75\end{array}$ & 22.47 & $8-40$ & 6.72 & $.66^{*}$ & - & & \\
\hline $\begin{array}{l}\text { EFS_positive emotion } \\
.79\end{array}$ & 11.17 & 4-20 & 4.32 & $.61 *$ & $.91^{*}$ & - & \\
\hline $\begin{array}{l}\text { EFS_reduction of negative emotion } \\
.74\end{array}$ & 11.30 & 4-20 & 3.32 & $.54 *$ & $.84^{*}$ & $.54^{*}$ & \\
\hline
\end{tabular}


Table 4 The correlation between DTFS, EFS and TRIM-18 and Heartland Forgiveness Scale (internal validity) $* p<.05$

\begin{tabular}{|c|c|c|c|c|}
\hline & DTFS & EFS_total & Positive emotion (EFS) & $\begin{array}{l}\text { Reduction } \\
\text { of negative emotion EFS }\end{array}$ \\
\hline Avoidance (TRIM) & $-.52 *$ & $-.67 *$ & $-.65^{*}$ & $-.50 *$ \\
\hline Revenge (TRIM) & $-.53^{*}$ & $-.48 *$ & $-.40 *$ & $-.46^{*}$ \\
\hline Benevolence (TRIM) & $.66^{*}$ & $.70 *$ & $.65^{*}$ & $.55^{*}$ \\
\hline General forgiveness (HFS) & $.26^{*}$ & $.20 *$ & .06 & $.32 *$ \\
\hline Positive forgiveness (P-scale) & $.27 *$ & $.20 *$ & $.12 *$ & $.25^{*}$ \\
\hline P-self & $.13 *$ & .04 & -.01 & $.10^{*}$ \\
\hline P-others & $.37 *$ & $.35^{*}$ & $.28^{*}$ & $.33^{*}$ \\
\hline P-situations & $.11 *$ & .07 & .01 & $.13^{*}$ \\
\hline Reduction of unforgiveness (N-scale) & $.17^{*}$ & $.14^{*}$ & -.00 & $.28^{*}$ \\
\hline N-self & .06 & .05 & -.07 & $.19 *$ \\
\hline N-others & $.26^{*}$ & $.19^{*}$ & $.11^{*}$ & $.24 *$ \\
\hline $\mathrm{N}$-situations & $.09 *$ & $.09 *$ & -.03 & $.21^{*}$ \\
\hline
\end{tabular}

episodic forgiveness (e.g. Thompson et al. 2005). Additionally, the differences between these two types of forgiveness are highlighted by their relationships with different variables (e.g. Riek and Mania 2012; Mróz and Kaleta 2017).

Furthermore, the results generally supported the criterionrelated validity. Participants with higher decisional forgiveness reported stronger positive affect and reflective thinking, and less depressive symptoms. Individuals with higher emotional forgiveness, especially in the reduction of negative feelings dimension, tended to obtain higher results in positive affect and lower results in negative affect, rumination, and negative aspects of health.. That is, episodic forgiveness was found to be linked with affect, reflection-rumination, and different psychosomatic symptoms in the expected direction. However, decisional and emotional forgiveness differ in terms of their correlates. DTFS was correlated only with few measures, while EFS scores were linked to all measures. These results confirmed expectations derived from conceptualization of decisional and emotional forgiveness as distinct processes with various sequelae (Worthington et al. 2007). Decisional forgiveness refers to victim's behavioral intentions of treating the offender well (Worthington et al. 2007). However, a person might not completely forgive the offender emotionally (Hook et al. 2009) or even still hold a resentment toward the offender, which is determined as "hollow forgiveness" (Baumeister et al. 1998). Thus, a mere decision to forgive might not reduce the victim's stress responses (Worthington et al. 2007). Our findings showed that decisional forgiveness was in fact not related to relief of negative affect and most psychosomatic symptoms. Emotional forgiveness, though

Table 5 The correlations of validation measurements and DTFS and EFS $(n=470)$ (external validity) $* p<.05$

\begin{tabular}{lcccc}
\hline & DTFS & EFS_total & Positive emotion (EFS) & Reduction of negative emotion (EFS) \\
\hline Positive affect & $.15^{*}$ & $.10^{*}$ & .06 & $.12^{*}$ \\
Negative affect & -.09 & -.09 & .03 & $-.21^{*}$ \\
Somatic symptoms & -.00 & -.00 & .07 & $-.10^{*}$ \\
Anxiety/insomnia & -.04 & -.04 & .06 & $-.16^{*}$ \\
Social dysfunctions & -.01 & -.04 & .03 & $-.13^{*}$ \\
Severe depression & $-.13^{*}$ & -.05 & .04 & $-.14^{*}$ \\
GHQ 28 - Total & -.06 & -.04 & .07 & $-.17^{*}$ \\
Rumination & -.05 & $.03 * 03$ & .06 & $-.16^{*}$ \\
Reflective thinking & $.11 *$ & .02 & & .03 \\
\hline
\end{tabular}


only in terms of reduction of negative emotions, was linked to decreased stress indicators, such as negative affect, rumination, and psychosomatic symptoms. Interestingly, positive dimension of emotional forgiveness, namely the presence of positive emotions, was not correlated to any measured variable usually related to forgiveness. This suggests that reduction of negative emotions toward the wrongdoer might be more important for one's well-being than evoking positive emotions toward him or her. The findings may also support the view by many scholars (Worthington and Wade 1999; Fincham et al. 2004) that negative and positive aspects of forgiveness are distinct dimensions with different antecedents and consequences expressed through different correlates.

It is noteworthy that the correlations between decisional and emotional forgiveness and the related variables are rather insignificant in our study. However, this is not unusual as we measured forgiveness as a state and other variables as a disposition. McCullough et al. (1998), who also examined episodic forgiveness and dispositional affectivity, found the only significant association between the Revenge subscale and negative affect, but not with positive affect. The Avoidance subscale was neither linked to negative, nor to positive affectivity. In turn, forgiveness as a disposition usually showed stronger correlation with dispositional measures of well-being. For example, all dimensions of trait forgiveness were substantially correlated with positive and negative affect, trait anger, anxiety, depression, and life satisfaction (Thompson et al. 2005).

Summing up, the Polish versions of DTFS and EFS can be considered reliable and valid tools measuring episodic forgiveness (decisional and emotional). The scales are intended for adults, however they can be used by older youth as well. The scales can be used in both individual and group research.

\section{Limitations}

Some limitations of the study should be pointed out. Firstly, the outcomes of the present study are based on responses of young participants, the majority of whom were female. Further research should test the psychometric properties of DTFS and EFS in a sample with various demographic characteristics. Secondly, the study used merely on self-report tools. The observed behavior or experimental study with self-report tools could be additional support for the validity of the scales.

Despite these limitations, our study makes an important contribution to the literature. As forgiveness has only scarcely been studied by Polish researchers, the current study offers a starting point for future research on forgiveness. As regards the results, some recommendations for future research can be made. Firstly, this study makes a valuable contribution to the field owing to translation and testing of psychometric properties of forgiveness measures in the Polish culture and language. However, researchers also require a reliable and valid original tool based on conceptualization of forgiveness by Polish participants. So far only the adapted or translated versions of original English scales were used in the Polish research on forgiveness (e.g. Mróz and Kaleta 2017; Kossakowska and Kwiatek 2017; Charzyńska et al. 2018; Kaleta and Mróz 2018). Meanwhile Polish culture is classified as a less individualistic than the culture of the United States and countries of Western Europe (Hofstede et al. 2010), which may affect the understanding of forgiveness. For instance, a collectivistic self-construal is associated to defining forgiveness as an interpersonal process involving reconciliation (Hook et al. 2012). Thus, the concept of forgiveness might be understood by Poles in a different manner than in more individualistic cultures, the more so that the Polish version of the two scales for dispositional forgiveness (Kaleta et al. 2016) obtained a different structure than their American equivalents.

Funding Information This work was supported by National Science Center, Poland No 2017/01/X/HS6/01835.

\section{Compliance with Ethical Standards}

Ethical Approval All procedures performed in studies involving human participants were in accordance with the ethical standards of the institutional and national research committee and with the 1964 Helsinki declaration and its later amendments or comparable ethical standards.

Informed Consent Informed consent was obtained from all participants.

Conflict of Interest On behalf of all authors, the corresponding author Justyna Mróz states that there is no conflict of interest.

Open Access This article is licensed under a Creative Commons Attribution 4.0 International License, which permits use, sharing, adaptation, distribution and reproduction in any medium or format, as long as you give appropriate credit to the original author(s) and the source, provide a link to the Creative Commons licence, and indicate if changes were made. The images or other third party material in this article are included in the article's Creative Commons licence, unless indicated otherwise in a credit line to the material. If material is not included in the article's Creative Commons licence and your intended use is not permitted by statutory regulation or exceeds the permitted use, you will need to obtain permission directly from the copyright holder. To view a copy of this licence, visit http://creativecommons.org/licenses/by/4.0/.

\section{References}

Bartholomaeus, J., \& Strelan, P. (2016). Just world beliefs and forgiveness: The mediating role of implicit theories of relationships. Personality and Individual Differences, 96, 106-110. https://doi. org/10.1016/j.paid.2016.02.081.

Baumeister, R. R., Exline, J. J., \& Sommer, K. L. (1998). The victim role, grudge theory, and two dimensions of forgiveness. In E. L. Worthington Jr. (Ed.), Dimensions of forgiveness (pp. 79-104). Radnor: Templeton Foundation Press.

Berry, J. W., Worthington, E. L., O'Connor, L. E., Parrott, L., \& Wade, N. G. (2005). Forgivingness, vengeful rumination, and affective traits. Journal of Personality, 73, 183-226. https://doi.org/10.1111/j. 1467-6494.2004.00308.x. 
Brzozowski, P. (2010). Skala uczuć pozytywnych i negatywnych SUPIN. Polska adaptacja PANAS Davida Watsona i Lee Anny Clark. Podręcznik., Warszawa: Pracownia Testów Psychologicznych. [Scale of positive and negative affects SUPIN: Polish adaptation of PANAS by David Watson \& Anna Clark]. Warszawa: PTP.

Charzyńska, E., Gruszczyńska, E., \& Heszen, I. (2018). Forgiveness and gratitude trajectories among persons undergoing alcohol addiction therapy. Addiction Research \& Theory, 1-12. https://doi.org/10. 1080/160663359.2018.1429595.

Davis, D. E., Hook, J. N., Van Tongeren, D. R., DeBlaere, C., Rice, K. G., \& Worthington Jr., E. L. (2015). Making a decision to forgive. Journal of Counseling Psychology, 62, 280-288. https://doi.org/10. 1037/cou0000054.

DiBlasio, F. A. (1998). The use of a decision-based forgiveness intervention within intergenerational family therapy. Journal of Family Therapy, 20, 77-96.

Dorn, K., Hook, J. N., Davis, D. E., Van Tongeren, D. R., \& Worthington, E. L. (2014). Behavioral methods of assessing forgiveness. Journal of Positive Psychology, 9, 75-80. https://doi.org/10.1080/17439760.2013.844267.

Duggi, D. B., \& Kamble, S. V. (2014). Decisional and emotional forgiveness in people of three religious groups in India. Indian Journal of Health and Wellbeing, 5, 24.

Enright, R. D. (1996). Counseling within the forgiveness triad: On forgiving, receiving forgiveness, and self-forgiveness. Counseling and Values, 40, $107-127$.

Exline, J. J., Worthington Jr., E. L., Hill, P., \& McCullough, M. E. (2003). Forgiveness and justice: A research agenda for social and personality psychology. Personality and Social Psychology Review, 7, 337-348.

Fincham, F. D., Beach, S. R., \& Davila, J. (2004). Forgiveness and conflict resolution in marriage. Journal of Family Psychology, 18, 72.

Fitzgibbons, R. P. (1986). The cognitive and emotive uses of forgiveness in the treatment of anger. Psychotherapy: Theory, 23, 629-633. https://doi.org/10.1037/h0085667.

Goldberg, D. (1978). General health questionnaire (GHQ-12). Windsor: NFER-Nelson.

Hofstede, G., Hofstede, G. J., \& Minkov, M. (2010). Cultures and organizations, software of the mind: Intercultural cooperation and its importance for survival. New York: McGraw Hill.

Hook, J. N., Worthington Jr., E. L., \& Utsey, S. O. (2009). Collectivism, forgiveness, and social harmony. The Counseling Psychologist, 37, 821-847. https://doi.org/10.1177/0011000008326546.

Hook, J. N., Worthington, E. L., Utsey, S. O., Davis, D. E., \& Burnette, J. L. (2012). Collectivistic self-construal and forgiveness. Counseling and Values, 57, 109-124.https://doi.org/10.1002/j.2161-007X.2012.00012.x.

Kaleta, K., \& Mróz, J. (2018). Forgiveness and life satisfaction across different age groups in adults. Personality and Individual Differences, 120, 17-23. https://doi.org/10.1016/j.paid.2017.08.008.

Kaleta, K., Mróz, J., \& Guzewicz, M. (2016). Polska adaptacja Skali Przebaczenia; heartland forgiveness scale [polish adaptation of heartland forgiveness scale]. Przeglad Psychologiczny, 59, 401-416.

Kossakowska, M. M., \& Kwiatek, P. (2017). Strategies of coping with transgressor - Polish validation of TRIM-18 questionnaire. Seminare. Poszukiwania naukowe, 38, 69-82. https://doi.org/10. 21852/sem.2017.4.06.

Kurniati, N. M. T., Worthington, E. L., Kristi Poerwandari, E., Ginanjar, A. S., \& Dwiwardani, C. (2017). Forgiveness in Javanese collective culture: The relationship between rumination, harmonious value, decisional forgiveness and emotional forgiveness. Asian Journal of Social Psychology, 20, 113-127. https://doi.org/10.1111/ajsp.12173.

Makowska, Z., \& Merecz, D. (2001). Polska adaptacja kwestionariuszy ogólnego stanu zdrowia Davida Goldberga: GHQ-12 i GHQ-28 [Polish adaptation of David Goldberg's general health questionnaire: GHQ-12, GHQ-28. Mental health evaluation based on D. Goldberg's questionnaires]. Łódź: Nofer Institute of Occupational Medicine.

Malcolm, W. M., \& Greenberg, L. S. (2000). Forgiveness as a process of change in individual psychotherapy. In M. McCullough, K.
Pargament, \& C. Thoresen (Eds.), Forgiveness: Theory, research, and practice (pp. 179-202). New York: Guilford.

McCullough, M. E., Worthington, E. L., \& Rachal, K. C. (1997). Interpersonal forgiving in close relationships. Journal of Personality and Social Psychology, 73, 321-336.

McCullough, M. E., Rachal, K. C., Sandage, S. J., Worthington Jr., E. L., Brown, S. W., \& Hight, T. L. (1998). Interpersonal forgiving in close relationships: II. Theoretical elaboration and measurement. Journal of Personality and Social Psychology, 75, 1586-1603.

McCullough, M. E., Root, L. M., \& Cohen, A. D. (2006). Writing about the benefits of an interpersonal transgression facilitates forgiveness. Journal of Consulting and Clinical Psychology, 74, 887-897. https://doi.org/10.1037/0022-006X.74.5.887.

Mróz, J., \& Kaleta, K. (2017). Cognitive and emotional predictors of episodic and dispositional forgiveness. Polish Psychological Bulletin, 48, 143-153. https://doi.org/10.1515/ppb-2017-0018.

Radoń, S. (2014). Kwestionariusz Ruminacji-Refleksyjności (polska adaptacja the rumination-reflection questionnaire). [Construction and validation of the polish version of the rumination-reflection questionnaire.]. Psychiatria, 2, 61-72.

Recoder, S., Gámiz, M., Worthington, E. L., Davis, D. E., \& FernándezCapo, M. (2019). Decisional forgiveness across spanish and american samples: Translation, validation, and measurement invariance of the decision to forgive scale. Current Psychology. https://doi.org/10. 1007/s12144-019-00368-w.

Riek, B. M., \& Mania, E. W. (2012). The antecedents and consequences of interpersonal forgiveness: A meta-analytic review. Personal Relationships, 19, 304-325.

Scherer, M., Worthington, E. L., Hook, J. N., Campana, K. L., West, S. L., \& Gartner, A. L. (2012). Forgiveness and cohesion in familial perceptions of alcohol misuse. Journal of Counseling and Development, 90, 160 168. https://doi.org/10.1111/j.1556-6676.2012.00021.x.

Thompson, L. Y., Snyder, C. R., Hoffman, L., Michael, S. T., Rasmussen, H. N., Billings, L. S., Heinze, L., Neufeld, J. E., Shorey, H. S., Roberts, J. C., \& Roberts, D. E. (2005). Dispositional forgiveness of self, others, and situations. Journal of Personality, 73, 313-359. https://doi.org/10.1111/j.1467-6494. 2005.00311.x.

Trapnell, P. D., \& Campbell, J. D. (1999). Private self-consciousness and the five-factor model of personality: Distinguishing rumination from reflection. Journal of Personality and Social Psychology, 76, 284-304.

Watkins, D. A., Hui, E. K., Luo, W., Regmi, M., Worthington Jr., E. L., Hook, J. N., \& Davis, D. E. (2011). Forgiveness and interpersonal relationships: A Nepalese investigation. The Journal of Social Psychology, 151, 150-161. https://doi.org/10.1080/ 00224540903368541.

Watson, D., Clark, L. A., \& Tellegen, A. (1988). Development and validation of brief measures of positive and negative affect: The PANAS scales. Journal of Personality and Social Psychology, 54, 1063.

Witvliet, C. V. O., DeYoung, N. J., Hofelich, A. J., \& DeYoung, P. A. (2011). Compassionate reappraisal and emotion suppression as alternatives to offense-focused rumination: Implications for forgiveness and psychophysiological well-being. The Journal of Positive Psychology, 6, 286-299. https://doi.org/10.1080/17439760.2011. 577091.

Worthington, E. L. (2005). More questions about forgiveness: Research agenda for 2005-2015. In E. L. Worthington Jr. (Ed.), Handbook of forgiveness (pp. 557-574). New York: Brunner Routledge.

Worthington, E. L. (2009). Forgiving and reconciling: Bridges to wholeness and Hope. Downers Grove: InterVarsity Press.

Worthington Jr., E. L., \& Wade, N. G. (1999). The social psychology of unforgiveness and forgiveness and implications for clinical practice. Journal of Social and Clinical Psychology, 18, 385-418.

Worthington, E. L., \& Scherer, M. (2004). Forgiveness is an emotion-focused coping strategy that can reduce health risks and promote health 
resilience: Theory, review, and hypotheses. Psychology \& Health, 19, 385-405. https://doi.org/10.1080/0887044042000196674.

Worthington, E. L., Witvliet, C. V. O., Pietrini, P., \& Miller, A. J. (2007).

Forgiveness, health, and well-being: A review of evidence for emotional versus decisional forgiveness, dispositional forgivingness, and reduced unforgiveness. Journal of Behavioral Medicine, 30, 291-302. https://doi.org/10.1007/s10865-007-9105-8.

Publisher's Note Springer Nature remains neutral with regard to jurisdictional claims in published maps and institutional affiliations. 